\title{
Evaluation of Sr and Cs ions adsorption capacities with zeolitic materials synthesized from various mass ratios of $\mathrm{NaOH}$ to coal fly ash
}

\author{
Jeong-Hak Choi ${ }^{1}$, Chang-Han Lee $^{2^{+}}$ \\ ${ }^{1}$ Department of Environmental Engineering, Catholic University of Pusan, Busan 46252, Korea \\ ${ }^{2}$ Department of Environmental Administration, Catholic University of Pusan, Busan 46252, Korea
}

\begin{abstract}
The adsorptive aqueous removal of $\mathrm{Sr}^{2+}$ and $\mathrm{Cs}^{+}$was performed using zeolitic materials prepared with fused coal fly ash (CFA) using a hydrothermal method. The influence of the mass ratio of $\mathrm{NaOH}$ to CFA of 0.3-1.2 in the synthesis of zeolitic material was evaluated its crystallization properties by X-ray diffraction (XRD) analysis. The zeolitic materials synthesized at the mass ratio of $\mathrm{NaOH}$ to CFA of $0.6-1.2$ could be identified to have the same location as the XRD peaks of Na-A zeolite at $2 \theta=7.18-34.18$. They appeared to be zeolitic materials which were crystalline particles with a cubic structure by scanning electron microscopy (SEM). The experimental adsorption data for $\mathrm{Sr}^{2+}$ and $\mathrm{Cs}^{+}$using the zeolitic materials were estimated satisfactory using pseudo- $2^{\text {nd }}$-order kinetics and Langmuir isotherm models. The highest maximum adsorption capacities $\left(\mathrm{q}_{\mathrm{m}}\right)$ of $147.6 \mathrm{mg} / \mathrm{g}$ for $\mathrm{Sr}^{2+}$ and $160.2 \mathrm{mg} / \mathrm{g}$ for $\mathrm{Cs}^{+}$were estimated by using the zeolitic material. This material demostrated superior crystallinity and was synthesized at a mass ratio of $\mathrm{NaOH}$ to CFA of 0.6. Consequently, the zeolitic material prepared from the fused CFA through the hydrothermal method could be used effectively for the adsorption of $\mathrm{Sr}^{2+}$ and $\mathrm{Cs}^{+}$in aqueous solutions.
\end{abstract}

Keywords: Cesium, Coal fly ash, Crystallization, Strontium, Zeolitic materials

\section{Introduction}

Nuclear power plants contain significant radioactive waste with radionuclides. They are considered one of the most hazardous contaminants, and their treatment has received much attention. Radioactive wastes released into the aquatic environment are known to damage the ecosystem - as in the case of the nuclear power plant accident at Fukushima in 2011. Nuclear fission reactions produce large amounts of hazardous radionuclides such as Cs and Sr ions. The Cs and Sr ions are accidentally or routinely released [1]. They have been deemed hazardous because of their relatively long half-life of 30 years. Their accumulation potential in animals and plants threatens human health and the environment $[2,3]$.

The technologies for the removal of Cs and Sr ions that are effective and feasible remove the ions from contaminated water by inorganic sorbents [1, 2, 4-6]. Coal fly ash (CFA) is discharged as solid waste from thermal power plants and recycled as raw materials, which are cement raw materials and concrete mixtures [7]. Various methods for reusing as source components are introduced because the main components of the CFA are $\mathrm{SiO}_{2}$ and $\mathrm{Al}_{2} \mathrm{O}_{3}$, which exist in the form of aluminosilicates in amorphous and crystalline phases such as quartz, mullite, and hematite [8]. Its composition allows it to become a precursor for the synthesis of zeolitic materials. Many studies have sought to improve the crystallinity of zeolitic materials with various synthetic conditions using the CFA [9-11]. Walek et al. [9] compared the synthesis efficiency of zeolitic materials according to the $\mathrm{CFA}$ and $\mathrm{NaOH}$ concentrations. Zeolitic materials were synthesized at a solid/liquid ratio of 4 in $2 \mathrm{M} \mathrm{NaOH}$ solution. Zeolitic materials have a relative crystallinity of $80 \%$ with the formation of a single-phase NaP1 zeolite. Yang et al. [10] prepared zeolitic materials with a relative crystallinity of $75.8 \%$ at a $\mathrm{Na}_{2} \mathrm{CO}_{3}$ and $\mathrm{NaOH}$ mass ratio of 2.8 in the zeolite synthesis
This is an Open Access article distributed under the terms of the Creative Commons Attribution Non-Commercial License (http://creativecommons.org/licenses/by-nc/3.0/) which permits unrestricted non-commercial use, distribution, and reproduction in any medium, provided the original work is properly cited.

Copyright (C) 2022 Korean Society of Environmental Engineers
Received November 29, 2020 Accepted February 13, 2021

${ }^{\dagger}$ Corresponding author

E-mail: chlee@cup.ac.kr

Tel: +82-51-510-0624

ORCID: 0000-0002-0641-1463 
process. Ye et al. [11] synthesized zeolitic materials from fused sodium carbonate and CFA mixture by a hydrothermal method at high temperatures.

Some researchers proposed experimental approaches to evaluate the removal performance of radioactive ions with adsorbents related to various zeolites $[1,5,6]$. The removal efficiencies of $\mathrm{Sr}^{2+}(69.0$ $\mathrm{mg} / \mathrm{g})$ and $\mathrm{Cs}^{+}(90.7 \mathrm{mg} / \mathrm{g})$ using a synthetic Na-A zeolite was evaluated using equilibrium data. They were represented using the pseudo- $2^{\text {nd }}$ order kinetic and Langmuir models [5]. The adsorption of $\mathrm{Cs}^{+}$using a zeolitic material from a bio-slag demonstrated a superior fit to the Langmuir and Freundlich models in comparison with the Temkin isotherm. The adsorption capability of the zeolitic material was $51.02 \mathrm{mg} / \mathrm{g}$ [12]. The adsorption ofr $\mathrm{Cs}^{2+}, \mathrm{Co}^{2+}$, and $\mathrm{Sr}^{2+}$ from clinoptilolite (natural zeolite) could be fitted by the Langmuir isotherm model [1]. The adsorption capacities of $\mathrm{Cs}^{2+}$, $\mathrm{Co}^{2+}$, and $\mathrm{Sr}^{2+}$ were $2.93,49.0$, and $9.8 \mathrm{mg} / \mathrm{g}$, respectively. Zeolitic materials with Na-A zeolite on the crystal surface were prepared from the CFA in Korea using the fusion/hydrothermal method [6]. It presented an adsorption capacity of $156.4 \mathrm{mg} / \mathrm{g}$ for $\mathrm{Sr}^{2+}$. However, it was difficult to find a correlation between the crystallinity of the zeolitic materials and $\mathrm{Sr}^{2+}$ and $\mathrm{Cs}^{+}$adsorptions in previous studies.

This study focused on the synthesis of zeolitic materials and used them as adsorbents to remove $\mathrm{Sr}^{2+}$ and $\mathrm{Cs}^{+}$in an aqueous solution. The CFA obtained from the Y power plant was synthesized into zeolitic materials through the fusion/hydrothermal method. The dependence of the synthesis of zeolitic materials upon the mass ratio of $\mathrm{NaOH}$ to $\mathrm{CFA}$ was confirmed by analyzing their crystallinity and crystal morphology. The zeolitic materials prepared with various mass ratios of $\mathrm{NaOH}$ to CFA were applied as adsorbents for the aqueous removal of $\mathrm{Sr}^{2+}$ and $\mathrm{Cs}^{+}$. Model fittings were also performed with the experimental data using the adsorption kinetic models (i.e., pseudo- $1^{\text {st }}$ and $2^{\text {nd }}$-order kinetic models) and adsorption isotherm models (i.e., Langmuir and Freundlich isotherm models) to evaluate the adsorption characteristics and capacities of $\mathrm{Sr}^{2+}$ and $\mathrm{Cs}^{+}$by the synthesized zeolitic materials.

\section{Materials and Methods}

\subsection{Materials}

The CFA was collected as a raw material at the $\mathrm{Y}$ thermal power plant in Korea. It was dried at $105^{\circ} \mathrm{C}$ in Pyrex glass containers for $10 \mathrm{~h}$. The standard Na-A zeolite sample (Z-CS) with CP grade was obtained from Cosmo Chemicals Co. Ltd (Korea). $\mathrm{NaOH}$ and $\mathrm{NaAlO}_{2}$ (EP grade) were obtained from Daejung Co. Ltd. (Korea). Stock solutions for batch adsorption experiments were prepared with $\mathrm{Sr}\left(\mathrm{NO}_{3}\right)_{2}$ and $\mathrm{CsNO}_{3}$ (ACS grade, Sigma-Aldrich, USA). Deionized water was used in all experiments.

\subsection{Preparation of Zeolitic Materials}

Zeolitic materials were prepared from the CFA according to the synthesis methods and conditions suggested in a previous study [13]. To increase the crystallinity of the zeolitic materials the $\mathrm{SiO}_{2} / \mathrm{Al}_{2} \mathrm{O}_{3}$ molar ratio was fixed at 2.5 and the mass ratios of

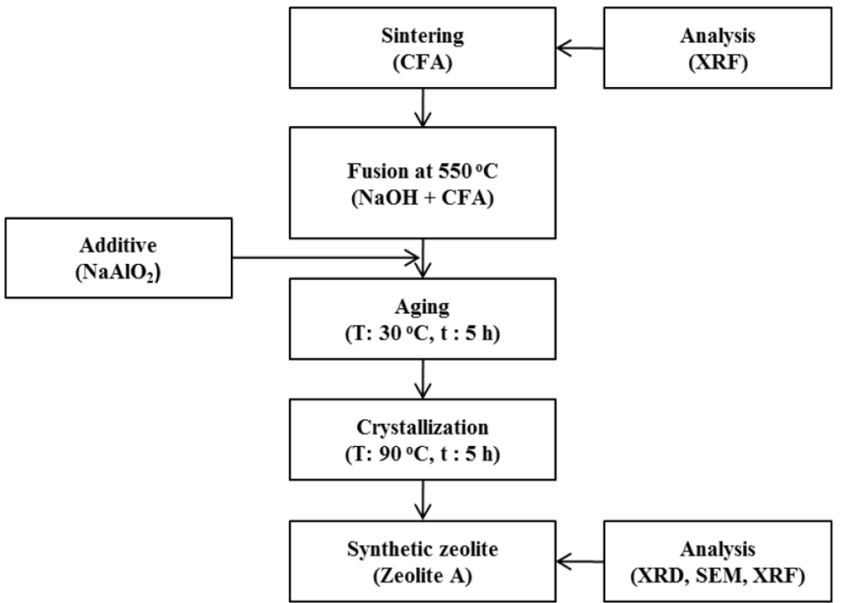

Fig. 1. Synthesis procedure for zeolitic materials.

$\mathrm{NaOH}$ to CFA were varied from 0.3 to 1.2 . The synthesis procedure for the zeolitic materials is shown in Fig. 1. The synthesis experiments were performed using a $0.2 \mathrm{~L}$ flat-bottom stainless-steel reactor equipped with an anchor-blade agitator and a temperature controller.

Ten grams of the CFA and $\mathrm{NaOH}$ powder (3, 6, 9 and $12 \mathrm{~g}$ ) were mixed and ground for $15 \mathrm{~min}$ in a mortar. They were fused at $550^{\circ} \mathrm{C}$ for $60 \mathrm{~min}$. The fused materials were pulverized into powder using a mortar. The powder was added to $3.51 \mathrm{~g}$ of $\mathrm{NaAlO}_{2}$. Deionized water $(100 \mathrm{~mL})$ was added to the mixture of the fused materials and $\mathrm{NaAlO}_{2}$. The dispersed solution was aged and then crystallized in the reactor. The synthetic products after all synthetic procedures were washed with deionized water until the filtrate reached $\mathrm{pH} 10$. They were dried at $110^{\circ} \mathrm{C}$ for $2 \mathrm{~h}$ in a dry oven.

\subsection{Characterization}

The crystallization properties of the synthetic materials were determined using an X-ray diffractometer (XRD, D8 Advance, Bruker AXS). The CFA, commercial Z-CS, and the prepared materials were analyzed with XRD patterns using a powder diffractometer with $\mathrm{Cu}-\mathrm{K} \alpha$ radiation. The samples were scanned under conditions of radiation wavelength $(\lambda)$ of $1.54 \AA$, diffraction angle $5^{\circ}<2 \theta<50^{\circ}$, and time constant of $0.02^{\circ}$ steps ( $3 \mathrm{~s}$ per step). The crystal morphology of the CFA and zeolitic materials was observed by a scanning electron microscopy (SEM, Hitachi S-4200). For SEM, the samples were mounted on a copper slab with double-sided tape and then coated with a thin layer of platinum.

\subsection{Adsorption Experiments}

The adsorption experiments for $\mathrm{Sr}^{2+}$ and $\mathrm{Cs}^{+}$were performed in $50 \mathrm{~mL}$-volumed conical centrifuge tubes (Falcon, 352070) at 25 ${ }^{\circ} \mathrm{C}$. Powdered commercial Na-A zeolite (Z-CS) or the prepared zeolitic material of $0.02 \mathrm{~g}$ was added to each conical centrifuge tube containing $50 \mathrm{~mL}$ of $\mathrm{Sr}^{2+}$ or $\mathrm{Cs}^{+}$stock solution. The mixed samples were stirred at $180 \mathrm{rpm}$ using a shaking incubator (VS-8480SF, Vision Scientific Co., Ltd.). During the adsorption reaction, the 
mixture was removed at regular intervals for the adsorption kinetic analysis and centrifuged for $3 \mathrm{~min}$ at 3,000 rpm (VS-5500i centrifuge, Vision Scientific Co., Ltd., Korea). After the centrifugation, the $\mathrm{Sr}^{2+}$ and $\mathrm{Cs}^{+}$concentrations in the supernatant were analyzed using an inductively coupled plasma mass spectrometer (ICP-MS 7900, Agilent). The initial $\mathrm{pH}$ was adjusted to 5.0 by adding 0.1 $\mathrm{M}$ of $\mathrm{HCl}$ or $\mathrm{NaOH}$. The $\mathrm{pH}$ measurements were conducted using a $\mathrm{pH}$ meter (model 420A, Orion).

The amount of $\mathrm{Sr}^{2+}$ and $\mathrm{Cs}^{+}$removed by the Na-A zeolite and zeolitic materials was calculated using Eq. (1).

$$
q=\frac{\left(C_{0}-C_{t}\right) V}{W}
$$

where $\mathrm{q}(\mathrm{mg} / \mathrm{g})$ is the adsorption capacity of $\mathrm{Sr}^{2+}$ or $\mathrm{Cs}^{+}$at time $\mathrm{t}, \mathrm{C}_{0}$ and $\mathrm{C}_{\mathrm{t}}(\mathrm{mg} / \mathrm{L})$ are the $\mathrm{Sr}^{2+}$ or $\mathrm{Cs}^{+}$concentrations at the $\mathrm{t}$ $=0$ and $\mathrm{t}$, respectively, $\mathrm{W}(\mathrm{g})$ is the dosage of the adsorbent, and $\mathrm{V}(\mathrm{L})$ is the volume of the solution.

\section{Results and Discussion}

\subsection{Synthesis of Zeolitic Materials from CFA}

Zeolitic materials were synthesized with mass ratios of $\mathrm{NaOH}$ to CFA varying from 0.3 to 1.2 via the synthesis procedure of our previous study [13]. The crystallization properties of the prepared materials were determined by XRD analysis and compared with that of the commercial Na-A zeolite (Z-CS) as a standard material. The XRD patterns of the raw material (CFA), the prepared materials, and the commercial Z-CS are shown in Fig. 2. The XRD result of the prepared sample with mass ratio of $\mathrm{NaOH}$ to CFA of 0.3 showed a different peak pattern and relatively weak peak intensities compared to those of the other prepared zeolitic materials and Z-CS. The XRD peaks of quartz and mullite were only observed in the sample with a mass ratio of $\mathrm{NaOH}$ to CFA of 0.3. Therefore, it was concluded that the zeolitic material could not be synthesized successfully at a mass ratio of $\mathrm{NaOH}$ to CFA of 0.3. The $2 \theta$ values of 20.82 and 26.62 indicated the XRD peak of quartz and the $2 \theta$ value of 35.24 indicated the XRD peak of mullite. Murayama et al. [14] suggested that Na-A zeolite could not be synthesized through hydrothermal synthesis with a $\mathrm{NaOH}$ concentration of $0.5 \mathrm{M}$ or less and only alumina and silica existed as the crystal forms. Previous study [15] reported the zeolitic material was able to be synthesized from the CFA using a fusion/hydrothermal method under low-alkali mass ratio of $\mathrm{NaOH}$ to CFA of 0.6. At the mass ratio of $\mathrm{NaOH}$ to CFA of 0.9 , some of the XRD peak corresponding to quartz ( $2 \theta$ value of 26.62) remained. However, at the mass ratio of $\mathrm{NaOH}$ to CFA of $0.6-1.2$, the $2 \theta$ values changed to $21.72,27.11$, and 34.21 , which is the XRD peak corresponding to Na-A zeolite. They could be identified as a successful synthesis of zeolitic materials because the peaks appeared at the same positions as those of the Na-A zeolite [16] in the $2 \theta$ range of 7.18 to 34.18 .

The SEM images of the raw material (CFA), the prepared samples, and the commercial Z-CS are shown in Fig. 3. CFA (a) consisted of spherical particles. The raw spherical particles were changed

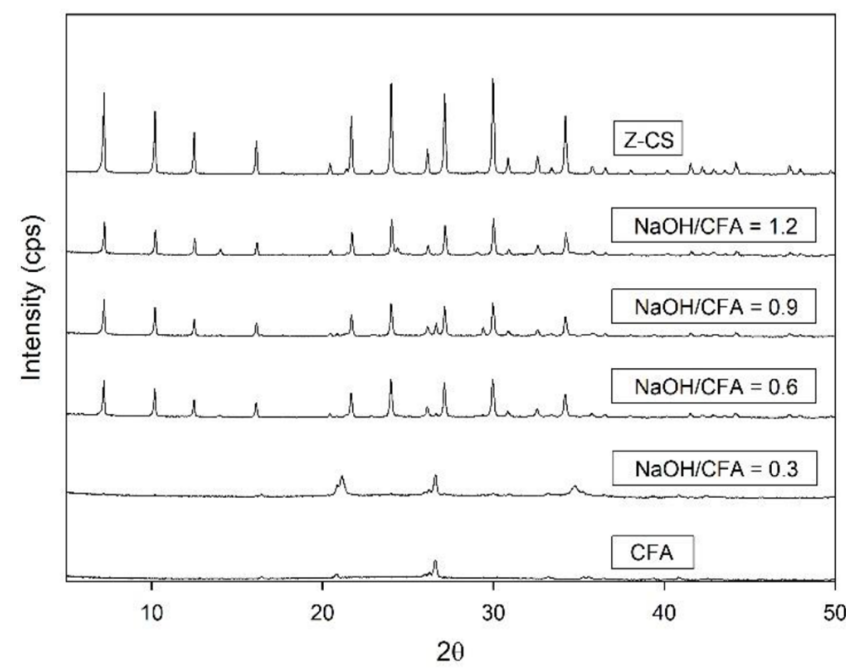

Fig. 2. XRD patterns of CFA, prepared materials (mass ratios of $\mathrm{NaOH}$ to CFA of 0.3-1.2), and commercial zeolite (Z-CS).

into rough and porous particles at the mass ratio of $\mathrm{NaOH}$ to $\mathrm{CFA}$ of 0.3 (b). Moreover, the surface roughness gradually developed on the originally smooth spherical particles according to the alkali fusion process with the synergism of $\mathrm{NaOH}$. The surface of the spherical particle was covered with the aggregate of cubic crystals at a mass ratio of $\mathrm{NaOH}$ to CFA of 0.6 (c). The cubic crystals on the particles decreased at the mass ratio of $\mathrm{NaOH}$ to CFA of 0.9 (d). Some of the cubic crystals were changed into sodalite crystals at the mass ratio of $\mathrm{NaOH}$ to CFA of 1.2 (e). From the SEM results, the prepared samples with the mass ratio of $\mathrm{NaOH}$ to CFA from 0.6 to 1.2 appeared to be zeolitic materials which were similar in morphological structure to the commercial Z-CS (Na-A zeolite (f)). The XRD patterns (Fig. 2) of the zeolitic materials with the mass ratios of $\mathrm{NaOH}$ to $\mathrm{CFA}$ from 0.6 to 1.2 were confirmed to be crystalline particles with the cubic structure of Na-A zeolite. The crystalline particle morphologies were similar shape to those of the zeolitic materials prepared from the CFA [14,17-18] and volcanic rocks [13]. Na-A zeolite and sodalite crystals were generated simultaneously from coal fly ash under high alkali conditions $\left(\mathrm{Na}_{2} \mathrm{CO}_{3}\right.$ and $\left.\mathrm{NaOH}\right)$ using fusion/hydrothermal synthesis [10].

\subsection{Adsorption Kinetic Analysis}

To analyze the adsorption kinetics of $\mathrm{Sr}^{2+}$ and $\mathrm{Cs}^{+}$with zeolitic materials, pseudo- $1^{\text {st }}$-order and pseudo- $2^{\text {nd }}$-order kinetic models were applied to fit the experimental adsorption data. The pseudo- $1^{\text {st }}$-order model for the adsorption kinetic analysis of solutes in aqueous solution to adsorbents is expressed as follows [19]:

$$
\frac{d q}{d t}=k_{1}\left(q_{e}-q\right)
$$

where $q$ and $q_{e}$ are the adsorption capacities (mg/g) at any time and equilibrium, respectively, and $k_{1}$ is the adsorption rate constant $(1 / \mathrm{h})$ for the pseudo- $\mathbf{~}^{\text {st }}$-order model. Integrating Eq. (2) for the boundary conditions $\mathrm{t}=0$ to $\mathrm{t}$ and $\mathrm{q}=0$ to $\mathrm{q}$ gives: 

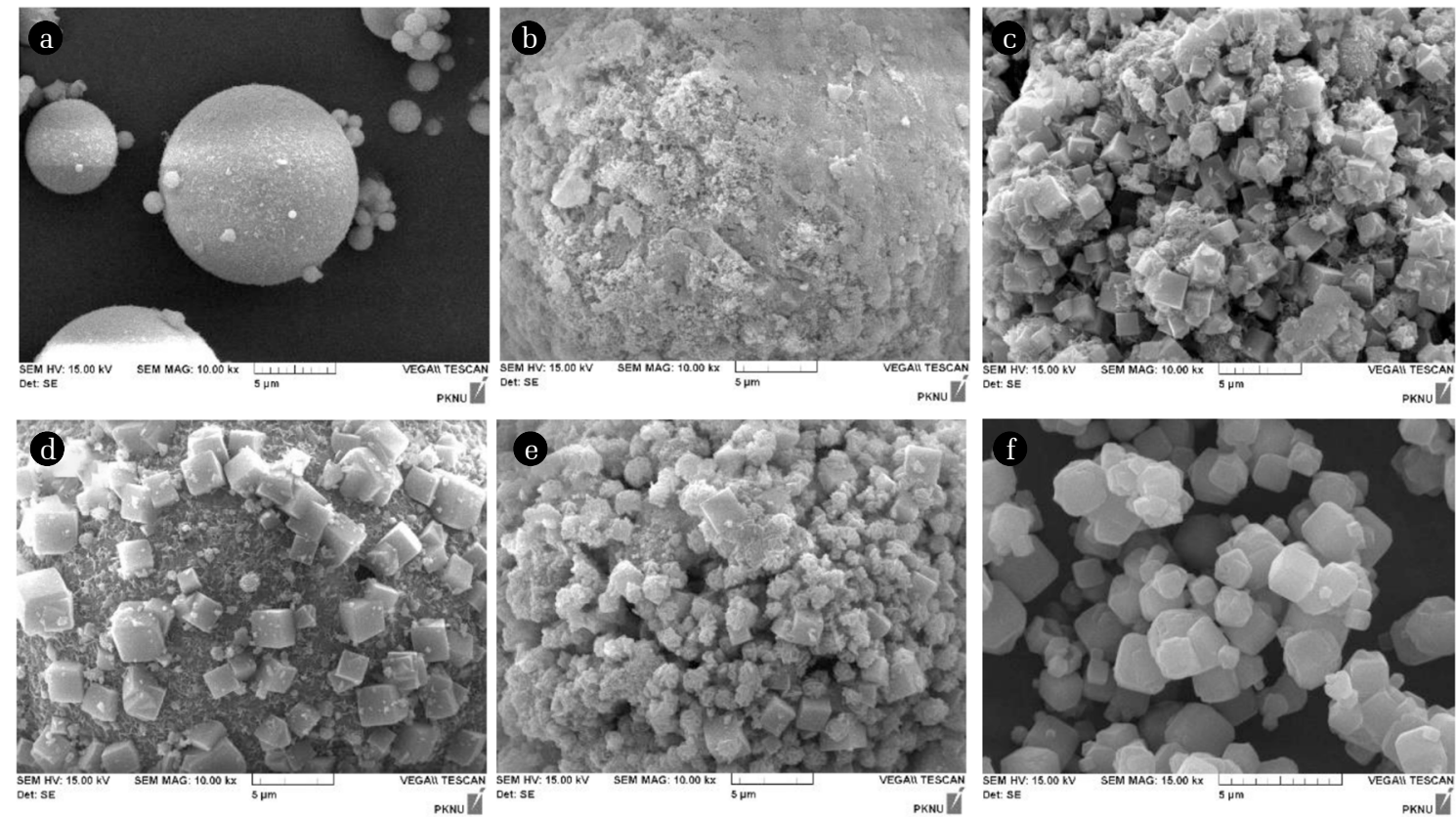

Fig. 3. SEM images of CFA $(\times 10,000)$, prepared materials $(\mathrm{NaOH} / \mathrm{CFA}=0.3-1.2)(\times 15,000)$, and commercial zeolite $(\mathrm{Z}-\mathrm{CS})(\times 15,000)((\mathrm{a})$ CFA; (b) $\mathrm{NaOH} / \mathrm{CFA}=0.3$; (c) $\mathrm{NaOH} / \mathrm{CFA}=0.6$; (d) $\mathrm{NaOH} / \mathrm{CFA}=0.9$; (e) $\mathrm{NaOH} / \mathrm{CFA}=1.2$; (f) Z-CS).

$$
\ln \left(q_{e}-q\right)=\ln \left(q_{e}\right)-k_{1} t
$$

The pseudo- $2^{\text {nd }}$-order model for the adsorption kinetic analysis of solutes from liquid to adsorbent phases is expressed as follows [5]:

$$
\frac{d q}{d t}=k_{2}\left(q_{e}-q\right)^{2}
$$

The integration of Eq. (4) for the boundary conditions $t=0$ to $\mathrm{t}$ and $\mathrm{q}=0$ to $\mathrm{q}$ gives:

$$
\frac{t}{q}=\frac{1}{k_{2} q_{e}^{2}}+\frac{1}{q_{e}} t
$$

where $k_{2}$ is the adsorption rate constant (g/mg.h) for the pseudo- $2^{\text {nd }}$-order model. A linear equation was then obtained from Eq. (5).

The experimental adsorption data of $\mathrm{Sr}^{2+}$ and $\mathrm{Cs}^{+}$using the synthesized zeolitic material (mass ratio of $\mathrm{NaOH}$ to $\mathrm{CFA}$ of 1.2) and the results of model fitting by the pseudo- $1^{\text {st }}$ and $2^{\text {nd }}$-order kinetic models are shown in Fig. 4. The adsorption capacities of $\mathrm{Sr}^{2+}$ and $\mathrm{Cs}^{+}$with the prepared zeolitic material increased gradually for the first $30 \mathrm{~min}$, after which they reached adsorption equilibrium within $120 \mathrm{~min}$. Other contact time results reported that the adsorption capacities of $\mathrm{Zn}^{2+}$ by $\mathrm{Na}-\mathrm{A}$ zeolite and $\mathrm{Cu}^{2+}$ by a ligand-embedded conjugate material reached equilibrium within approximately $120 \mathrm{~min}$ and $50 \mathrm{~min}$, respectively [20, 21]. The kinetic parameters of $\mathrm{Sr}^{2+}$ and $\mathrm{Cs}^{+}$obtained from estimating the experimental data to Eq. (3) and (5) are summarized in Table 1.

In the pseudo- $1^{\text {st }}$ and $2^{\text {nd }}$-order kinetic models, the plot of $\ln \left(q_{e}-q\right)$ versus $t$ and $t / q_{t}$ versus $t$ gives a linear line with a slope of $k_{1}$

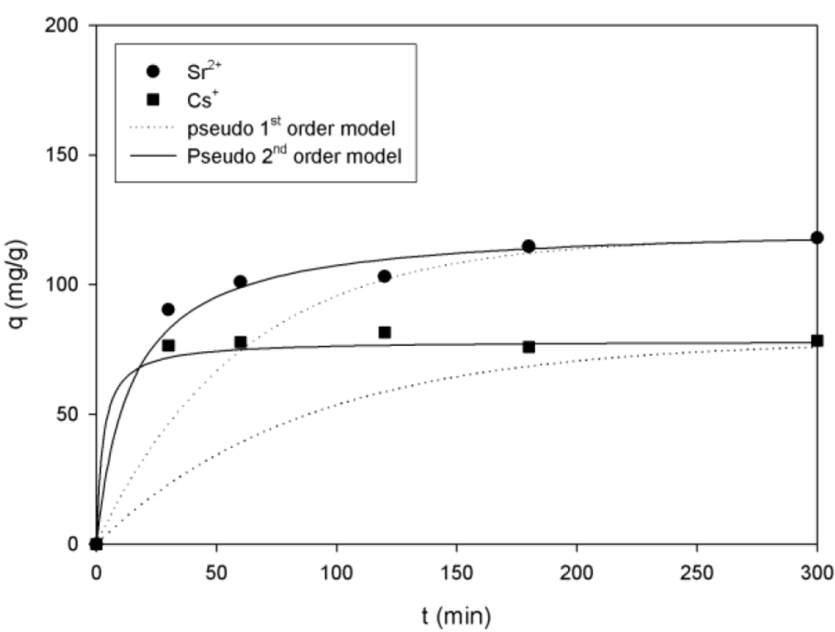

Fig. 4. Kinetic results and model fittings for the adsorption of $\mathrm{Sr}^{2+}$ and $\mathrm{Cs}^{+}$using the zeolitic material synthesized with the mass ratio of $\mathrm{NaOH}$ to CFA of 1.2 (adsorbent dosage $=0.02 \mathrm{~g} / 0.05 \mathrm{~L}$ ).

and $1 / q_{e}$ and intercept of $\ln \left(q_{e}\right)$ and $1 / k_{2} q_{e}^{2}$, respectively. $q_{e}, k_{1}$, and $k_{2}$ were calculated from the slope and intercept of the kinetic models. As shown in Table 1, the $q_{e}$ values estimated with the pseudo- $1^{\text {st }}$-order kinetic model differed considerably from the experimental adsorption capacities $\left(q_{e, \exp }\right)$ calculated directly from the experimental data, whereas the $q_{e}$ values by the pseudo- $2^{\text {nd }}$-order model fitting showing high correlations $\left(\mathrm{r}^{2}\right)$ were similar to the $q_{e, \exp }$ in both cases of $\mathrm{Sr}^{2+}$ and $\mathrm{Cs}^{+}$adsorption. The $\mathrm{r}^{2}$ values of the pseudo-2 ${ }^{\text {nd }}$-order model for $\mathrm{Sr}^{2+}$ and $\mathrm{Cs}^{+}$ were 0.9979 and 0.9991, respectively. Consequently, the adsorp- 
Table 1. Adsorption Kinetic Parameters of $\mathrm{Sr}^{2+}$ and $\mathrm{Cs}^{+}$Using the Zeolitic Material Synthesized with the Mass Ratio of $\mathrm{NaOH}$ to $\mathrm{CFA}$ of 1.2

\begin{tabular}{|c|c|c|c|c|c|c|c|c|}
\hline \multirow[b]{2}{*}{ Ion } & \multirow[b]{2}{*}{$\begin{array}{c}\mathrm{C}_{0} \\
(\mathrm{mg} / \mathrm{L})\end{array}$} & \multirow[b]{2}{*}{$\begin{array}{c}\mathbf{q}_{\mathbf{e}, \exp } \\
(\mathrm{mg} / \mathrm{g})\end{array}$} & \multicolumn{3}{|c|}{ pseudo- $\mathbf{1}^{\text {st }}$-order kinetic model } & \multicolumn{3}{|c|}{ pseudo-2 ${ }^{\text {nd }}$-order kinetic model } \\
\hline & & & $\begin{array}{c}q_{e} \\
(\mathrm{mg} / \mathrm{g})\end{array}$ & $\begin{array}{c}k_{1} \\
(1 / h)\end{array}$ & $\mathbf{r}^{2}$ & $\begin{array}{c}q_{e} \\
(\mathrm{mg} / \mathrm{g})\end{array}$ & $\begin{array}{c}\mathbf{k}_{2} \\
(\mathrm{mg} / \mathrm{g} \cdot \mathbf{h})\end{array}$ & $\mathbf{r}^{2}$ \\
\hline $\mathrm{Sr}^{2+}$ & 50 & 118.0 & 70.9 & 0.0166 & 0.8733 & 123.0 & 0.0056 & 0.9979 \\
\hline $\mathrm{Cs}^{+}$ & 50 & 78.4 & 51.5 & 0.0822 & 0.9201 & 78.4 & 0.0469 & 0.9991 \\
\hline
\end{tabular}

tion kinetics for $\mathrm{Sr}^{2+}$ and $\mathrm{Cs}^{+}$using the zeolitic material could be well estimated by the pseudo- $2^{\text {nd }}$-order kinetic model. El-Rahman et al. [22] reported that the experimental adsorption results of $\mathrm{Sr}^{2+}$ and $\mathrm{Cs}^{+}$with a Na-A zeolite prepared from the CFA were described to the pseudo- $2^{\text {nd }}$-order kinetic model better than the pseudo- $1^{\text {st }}$-order model. El-Kamash [5] also mentioned that the adsorptive removal kinetics of $\mathrm{Sr}^{2+}$ and $\mathrm{Cs}^{+}$using a $\mathrm{Na}-\mathrm{A}$ zeolite could be predicted more accurately with the pseudo- $2^{\text {nd }}$-order model.

\subsection{Adsorption Isotherm Analysis}

The adsorption equilibrium data of $\mathrm{Sr}^{2+}$ and $\mathrm{Cs}^{+}$were obtained experimentally and then the Langmuir and Freundlich models were applied for the adsorption isotherm analysis.

Langmuir model is expressed as follows [23]:

$$
q_{e}=\frac{k_{L} q_{m} C_{e}}{1+k_{L} C_{e}}
$$

where $q_{m}$ is the maximum adsorption capacity $(\mathrm{mg} / \mathrm{g}), C_{e}$ is the equilibrium concentration of the adsorbate $(\mathrm{mg} / \mathrm{L})$, and $k_{L}$ is the Langmuir constant (L/mg).

Freundlich model is expressed as follows [24]:

$$
q_{e}=k_{F} C_{e}^{\frac{1}{n}}
$$

where $k_{F}$ and $1 / n$ are the Freundlich constants $\left((\mathrm{mg} / \mathrm{g})(\mathrm{L} / \mathrm{mg})^{1 / \mathrm{n}}\right)$ and a constant indicating the adsorption strength, respectively.
The experimental adsorption data of $\mathrm{Sr}^{2+}$ and $\mathrm{Cs}^{+}$and model fitting data are shown in Fig. 5. Model fitting was performed for both the commercial zeolite (Z-CS) and the zeolitic materials synthesized with various mass ratios of $\mathrm{NaOH}$ to CFA. The adsorption isotherm parameters for the Langmuir and Freundlich models were estimated for all adsorption cases and are presented in Table 2. The $\mathrm{r}^{2}$ values of the Langmuir model were found to be comparatively higher than those of the Freundlich model. The $q_{m}$ for $\mathrm{Sr}^{2+}$ estimated by the Langmuir model was $123.6-147.6 \mathrm{mg} / \mathrm{g}$ at the mass ratio of $\mathrm{NaOH}$ to CFA of $0.6-1.2$, and $16.9 \mathrm{mg} / \mathrm{g}$ at the mass ratio of $\mathrm{NaOH}$ to CFA of 0.3 . For the adsorption of $\mathrm{Cs}^{+}$, the $q_{m}$ values were calculated as $124.9-160.2 \mathrm{mg} / \mathrm{g}$ at the mass ratio of $\mathrm{NaOH}$ to CFA of $0.6-1.2$, and $17.9 \mathrm{mg} / \mathrm{g}$ at the mass ratio of $\mathrm{NaOH}$ to CFA of 0.3. From these results, it was found that zeolitic material was not successfully synthesized at the mass ratio of $\mathrm{NaOH}$ to CFA of 0.3 and its function as an adsorbent was not sufficiently exhibited. Notably, $q_{m}$ was shown to be higher at the mass ratio of $\mathrm{NaOH}$ to CFA of 0.6 than at mass ratios of 0.9 and 1.2 in both adsorption cases of $\mathrm{Sr}^{2+}$ and $\mathrm{Cs}^{+}$and its $\mathrm{q}_{\mathrm{m}}$ value was $147.6 \mathrm{mg} / \mathrm{g}$ and $160.2 \mathrm{mg} / \mathrm{g}$, respectively. These results indicate that the zeolitic materials covered with homogeneous cubic crystals synthesized at the mass ratio of $\mathrm{NaOH}$ to CFA of 0.6 (Fig. 3(c)) can be a better adsorbent than those synthesized at mass ratios of 0.9 and 1.2 (Fig. 3(d) and (e)). The $q_{m}$ values for $\mathrm{Sr}^{2+}$ and $\mathrm{Cs}^{+}$using natural zeolite (clinoptilolite) by the Langmuir model were calculated to 9.80 and $49.02 \mathrm{mg} / \mathrm{g}$, respectively [1]. Consequently, the synthesized zeolitic material with a mass ratio of $\mathrm{NaOH}$ to CFA of 0.6 in this study could be a superior adsorbent for the aqueous removal of $\mathrm{Sr}^{2+}$ and $\mathrm{Cs}^{+}$.
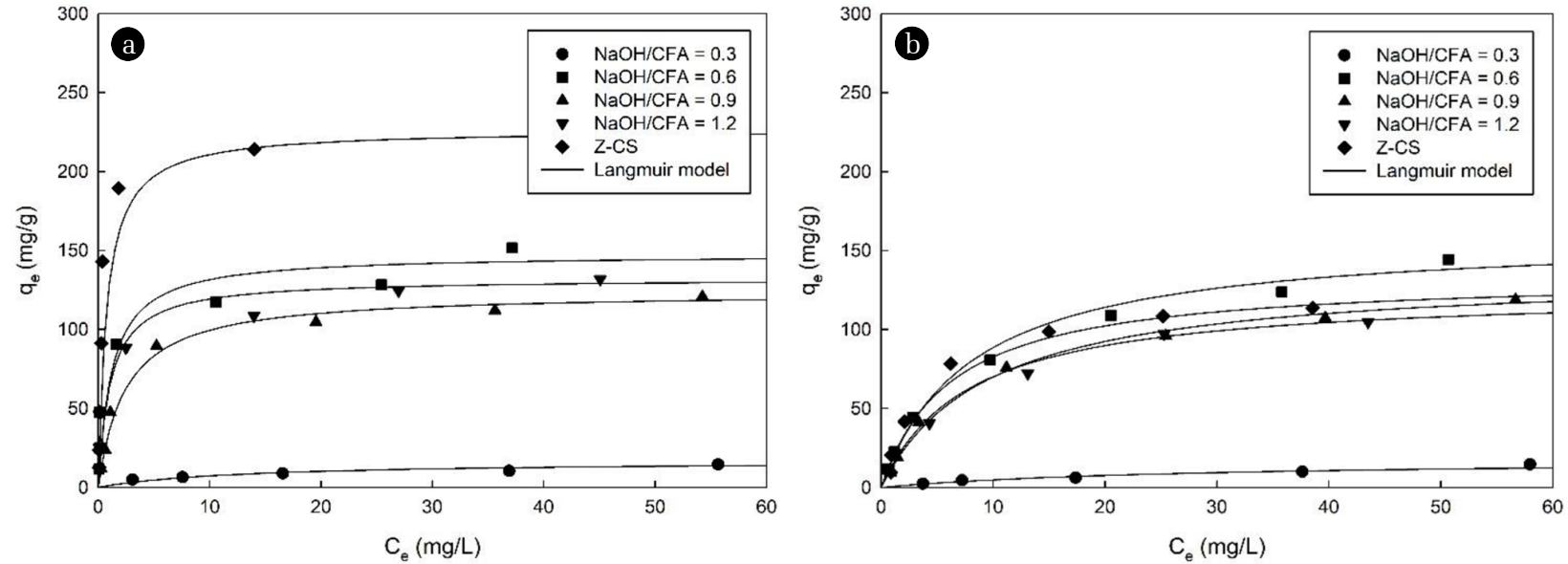

Fig. 5. Adsorption isotherm results and model fittings for the adsorption of (a) $\mathrm{Sr}^{2+}$ and (b) $\mathrm{Cs}^{+}$using the zeolitic materials synthesized with the mass ratios of $\mathrm{NaOH}$ to CFA of 0.3-1.2 and commercial Z-CS (adsorbent dosage $=0.02 \mathrm{~g} / 0.05 \mathrm{~L}$ ). 
Table 2. Adsorption Isotherm Parameters of $\mathrm{Sr}^{2+}$ and $\mathrm{Cs}^{+}$Using the Zeolitic Materials Synthesized with the Mass Ratios of $\mathrm{NaOH}$ to $\mathrm{CFA}$ of 0.3-1.2 and Commercial Z-CS

\begin{tabular}{|c|c|c|c|c|c|c|c|}
\hline \multirow[b]{2}{*}{ Mass ratio } & \multirow[b]{2}{*}{ Ion } & \multicolumn{3}{|c|}{ Langmuir model } & \multicolumn{3}{|c|}{ Freundlich model } \\
\hline & & $\begin{array}{c}\mathrm{q}_{\mathrm{m}} \\
(\mathrm{mg} / \mathrm{g})\end{array}$ & $\begin{array}{c}\mathbf{k}_{\mathbf{L}} \\
(\mathrm{L} / \mathbf{m g})\end{array}$ & $\mathbf{r}^{2}$ & $\begin{array}{c}\mathbf{k}_{\mathbf{F}} \\
\left(\mathrm{mg} / \mathrm{g} \cdot(\mathrm{L} / \mathrm{mg})^{1 / \mathbf{n}}\right)\end{array}$ & $1 / n$ & $\mathbf{r}^{2}$ \\
\hline \multirow{2}{*}{ Z-CS } & $\mathrm{Sr}^{2+}$ & 226.5 & 1.3289 & 0.9864 & 99.6973 & 0.4845 & 0.6378 \\
\hline & $\mathrm{Cs}^{+}$ & 134.3 & 0.1602 & 0.9759 & 19.0853 & 0.5665 & 0.8653 \\
\hline \multirow{2}{*}{0.3} & $\mathrm{Sr}^{2+}$ & 16.9 & 0.0757 & 0.9765 & 3.3514 & 0.3361 & 0.9804 \\
\hline & $\mathrm{Cs}^{+}$ & 17.9 & 0.0368 & 0.7950 & 1.3316 & 0.5400 & 0.9256 \\
\hline \multirow{2}{*}{0.6} & $\mathrm{Sr}^{2+}$ & 147.6 & 0.8190 & 0.9886 & 51.8145 & 0.3288 & 0.8207 \\
\hline & $\mathrm{Cs}^{+}$ & 160.2 & 0.1237 & 0.9915 & 20.3749 & 0.5343 & 0.9716 \\
\hline \multirow{2}{*}{0.9} & $\mathrm{Sr}^{2+}$ & 123.6 & 0.4117 & 0.9982 & 31.1806 & 0.3958 & 0.8895 \\
\hline & $\mathrm{Cs}^{+}$ & 136.5 & 0.1051 & 0.9966 & 14.9079 & 0.5652 & 0.9393 \\
\hline \multirow{2}{*}{1.2} & $\mathrm{Sr}^{2+}$ & 132.2 & 0.9261 & 0.9966 & 48.6992 & 0.3065 & 0.8482 \\
\hline & $\mathrm{Cs}^{+}$ & 124.9 & 0.1281 & 0.9977 & 17.1865 & 0.4989 & 0.9676 \\
\hline
\end{tabular}

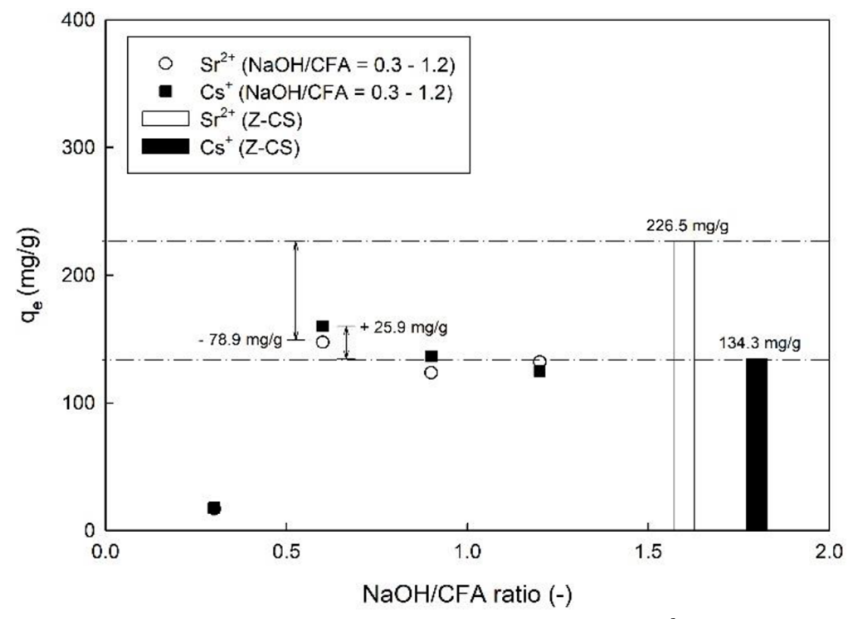

Fig. 6. Comparison of the adsorption capacities of $\mathrm{Sr}^{2+}$ and $\mathrm{Cs}^{+}$by the prepared zeolitic materials and commercial Z-CS.

The $q_{m}$ values of the zeolitic materials prepared with various mass ratios of $\mathrm{NaOH}$ to $\mathrm{CFA}$ and the commercial zeolite (Z-CS) are compared in Fig. 6. The $\mathrm{q}_{\mathrm{m}}$ of the zeolitic material with a mass ratio of $\mathrm{NaOH}$ to $\mathrm{CFA}$ of 0.6 for $\mathrm{Sr}^{2+}(147.6 \mathrm{mg} / \mathrm{g})$ was approximately 35\% lower than that of the commercial Z-CS (226.5 mg/g), however, the $\mathrm{q}_{\mathrm{m}}$ of the zeolitic material for $\mathrm{Cs}^{+}(160.2 \mathrm{mg} / \mathrm{g})$ was higher than that of the Z-CS (134.3 mg/g). In a previous study on the adsorptive removal of $\mathrm{Sr}^{2+}$ and $\mathrm{Cs}^{+}$using a Na-A zeolite synthesized from the CFA, the maximum adsorption capacity of the Na-A zeolite was reported to be $303.00 \mathrm{mg} / \mathrm{g}$ for $\mathrm{Sr}^{2+}$ and 207.47 $\mathrm{mg} / \mathrm{g}$ for $\mathrm{Cs}^{+}$[5]. Therefore, the zeolitic material synthesized from the CFA in this study seems to be an efficient adsorbent for the removal of $\mathrm{Sr}^{2+}$ and $\mathrm{Cs}^{+}$. It can also be a cost-effective adsorbent through synthesis under low alkali conditions.

\section{Conclusions}

Zeolitic materials were successfully prepared from coal fly ash (CFA) via the fusion and hydrothermal method by changing the mass ratio of $\mathrm{NaOH}$ to $\mathrm{CFA}$. In the XRD and SEM analyses, the prepared zeolitic materials confirmed the morphological structure with highly crystalline particles covered with cubic crystals. Zeolitic materials with the XRD peak pattern of Na-A type zeolite could be synthesized at the mass ratios of $\mathrm{NaOH}$ to CFA of 0.6-1.2, and the zeolitic materials were covered with cubic crystals much more homogeneously at a mass ratio of $\mathrm{NaOH}$ to CFA of 0.6 , which is a cost-effective, synthetic condition to synthesize zeolitic materials from CFA. The prepared zeolitic materials were used as adsorbents for the removal of $\mathrm{Sr}^{2+}$ and $\mathrm{Cs}^{+}$in an aqueous solution. The experimental adsorption data for $\mathrm{Sr}^{2+}$ and $\mathrm{Cs}^{+}$were described well by the Langmuir isotherm model, and the zeolitic material synthesized with the mass ratio of $\mathrm{NaOH}$ to $\mathrm{CFA}$ of 0.6 exhibited the highest maximum adsorption capacity $\left(q_{m}\right)$ in both $\mathrm{Sr}^{2+}$ and $\mathrm{Cs}^{+}$adsorption. Furthermore, the $q_{m}$ of the prepared material with a mass ratio of 0.6 was even higher than that of the commercial Z-CS in $\mathrm{Cs}^{+}$ adsorption. As a result, it could be suggested that the zeolitic materials prepared from CFA through the fusion and hydrothermal method can be applied as an adequate for the removal of $\mathrm{Sr}^{2+}$ and $\mathrm{Cs}^{+}$.

\section{Acknowledgments}

This paper was supported by Basic Science Research Program through the National Research Foundation of Korea (NRF) funded by the Ministry of Education (NRF-2017R1D1A1B03030350) and by Research Fund offered from Catholic University of Pusan in 2018.

\section{Author Contributions}

J.H.C. (Professor) conducted the adsorption experiments and wrote the manuscript; C.H.L. (Professor) synthesized adsorbents, performed the adsorption experiments and wrote the manuscript.

\section{References}

1. Smiciklas I, Dimovic S, Plecas I. Removal of $\mathrm{Cs}^{1+}, \mathrm{Sr}^{2+}$ and 
$\mathrm{Co}^{2+}$ from aqueous solutions by adsorption on natural clinoptilolite. Appl. Clay Sci. 2007;35:139-144.

2. Wang M, Xu L, Peng J, Zhai M, Li J, Wei G. Adsorption and desorption of $\mathrm{Sr}$ (II) ions in the gels based on polysaccharide derivatives. J. Hazard. Mater. 2009;171:820-826.

3. Munthali MW, Johan E, Aono H, Matsue N. $\mathrm{Cs}^{+}$and $\mathrm{Sr}^{2+}$ adsorption selectivity of zeolites in relation to radioactive decontamination. J. Asian Cera. Soc. 2015;3:245-250.

4. Vereshchagina TA, Vereshchagin SN, Shishkina NN, Vasilieva NG, Solovyov LA, Anshits AG. Microsphere zeolite materials derived from coal fly ash cenospheres as precursors to mineral-like aluminosilicate hosts for $135,137 \mathrm{Cs}$ and 90Sr. J. Nucl. Mater. 2013;437:11-18.

5. El-Kamash AM. Evaluation of zeolite A for the sorptive removal of $\mathrm{Cs}^{+}$and $\mathrm{Sr}^{2+}$ ions from aqueous solutions using batch and fixed bed column operations. J. Hazard. Mater. 2008;151: 432-445.

6. Lee CH, Park JM, Lee MG. Adsorption characteristics of Sr(II) and Cs(I) ions by zeolite synthesized from coal fly ash. J. Environ. Sci. Int. 2014;23:1987-1998.

7. Gollakota ARK, Volli V, Shu CH. Progressive utilisation prospects of coal fly ash: A review. Sci. Total Environ. 2019;672: 951-989.

8. Bieseki L, Penha FG, Pergher SBC. Zeolite A synthesis employing a Brazilian coal ash as the silicon and aluminum source and its applications in adsorption and pigment formulation. Mater. Res. 2013;16:38-43.

9. Wałek TT, Saito F, Zhang Q. The effect of low solid/liquid ratio on hydrothermal synthesis of zeolites from fly ash. Fuel 2008;87:3194-3199.

10. Yang L, Qian X, Yuan P, et al. Green synthesis of zeolite 4A using fly ash fused with synergism of $\mathrm{NaOH}$ and $\mathrm{Na}_{2} \mathrm{CO}_{3}$. J. Clean. Prod. 2019;212:250-260.

11. Ye Y, Zeng X, Qian W, Wang M. Synthesis of pure zeolites from supersaturated silicon and aluminum alkali extracts from fused coal fly ash. Fuel 2008;87:1880-1886.

12. Khandaker S, Toyohara Y, Saha GC, Awual MR, Kuba T. Development of synthetic zeolites from bio-slag for cesium ad-
sorption:Kinetic, isotherm and thermodynamic studies. J. Water Process Eng. 2020;33:101055.

13. Lee MG, Park JW, Kam SK, Lee CH, Synthesis of Na-A zeolite from Jeju Island scoria using fusion/hydrothermal method. Chemosphere 2018;2017:203-208.

14. Murayama N, Yamamoto H, Shibata J. Mechanism of zeolite synthesis from coal fly ash by alkali hydrothermal reaction. Int. J. Miner. Process 2002;64:1-17.

15. Choi JH, Lee CH. Adsorption and desorption characteristics of Sr, Cs, and Na Ions with Na-A zeolite synthesized from coal fly ash in low-alkali condition. J. Environ. Sci. Int. 2019;28:561-570.

16. Treacy MMJ, Higgins JB. Collection of simulated XRD powder patterns for zeolites. Elsevier: Amsterdam; 2001.

17. Tanaka H, Fujii A. Effect of stirring on the dissolution of coal fly ash and synthesis of pure form Na-A and -X zeolites by two step process. Adv. Powd. Tech. 2009;20:473-479.

18. Wang CF, Li JS, Wang LJ, Sun XY. Influence of NaOH concentrations on synthesis of pure-form zeolite A from fly ash using two-stage method. J. Hazard. Mater. 2008;155:58-64.

19. Lagergren S. Zur theorie der sogenannten adsorption geloster stoffe, Kungliga Svenska Vetenskapsakademiens. Handlingar 1898;24:1-39.

20. Nibou D, Mekatel H, Amokrane S, Barkat M, Trari M. Adsorption of $\mathrm{Zn}^{2+}$ ions onto $\mathrm{NaA}$ and $\mathrm{NaX}$ zeolites: Kinetic, equilibrium and thermodynamic studies. J. Hazard. Mater. 2010;173: 637-646.

21. Awual MR, Hasan MM, Khaleque MA, Sheikh MC. Treatment of copper(II) containing wastewater by a newly developed ligand based facial conjugate materials. Chem. Eng. J. 2016;288: 368-376.

22. El-Rahman KMA, El-Sourougy MR, Abdel-Monem NM, Ismail IM. Modeling the sorption kinetics of cesium and strontium ions on zeolite A. J. Nuclear Radiochem. Sci. 2006;7:21-27.

23. Langmuir I. The adsorption of gases on plane surface of glass, mica and platinum. J. Am. Chem. Soc. 1918;40:1361-1403.

24. Freundlich HMF. Over the adsorption in solution. J. Phys. Chem. 1906;57:385-470. 